\title{
Porto Digital: Um Exemplo de Responsabilidade Social
}

\author{
Ivaldir H. de Farias Junior ${ }^{1}$, Itala Celly Bezerra de Farias ${ }^{2}$, José Gilson de A. Texeira ${ }^{1}$, Ana C. Pereira ${ }^{3}$ \\ ${ }^{1}$ Universidade Federal de Pernambuco (UFPE) - Recife - PE - Brasil \\ ${ }^{2}$ Universidade Estadual Vale do Acaraú (UVA) - Recife - PE - Brasil \\ ${ }^{3}$ Faculdade Maurício de Nassau - Recife - PE - Brasil
}

ivaldirjr@gmail.com, italacelly@hotmail.com, igtfilho@gmail.com, a_cris_pereira@hotmail.com

\begin{abstract}
The Social Responsibility has been a subject very argued in the enterprise way, since many companies if have used of this practical through diverse programs in the social area, looking for to demonstrate its social function before the community where she is inserted. Based in a Social Project of the Digital Port, intitled In project' to form, this article has as objective, to show to the importance of the social responsibility and its influence in the communities of Pilar and Peixinhos in the city of Recife in Pernambuco. It was possible to observe that the project promoted the inclusion of the young in a new context: the technology market. The companies with which the young had passed if to relate to give services are of a competitive, modern segment and mainly with specific demands. These relationships had considered to the young the construction of new values, different of the future vision that had before participating of the project.
\end{abstract}

Keywords: Social Responsibility, Project In'formar, Communities Pilar e Peixinhos.

Resumo. A Responsabilidade Social tem sido um tema muito discutido no meio empresarial, visto que muitas empresas têm se utilizado desta prática através de diversos programas na área social, procurando demonstrar sua função social perante a comunidade em que está inserida. Baseado em um Projeto Social do Porto Digital, intitulado projeto In'formar, este artigo tem como objetivo, mostrar a importância da responsabilidade social e a sua influência nas comunidades do Pilar e Peixinhos na cidade do Recife em Pernambuco. Foi possível observar que o projeto promoveu a inclusão dos jovens em um novo contexto: o mercado de tecnologia. As empresas com os quais os jovens passaram a se relacionar para prestar serviços são de um segmento competitivo, moderno e principalmente com demandas específicas. Esses relacionamentos propuseram aos jovens a construção de novos valores, diferente da visão de futuro que tinham antes de participarem do projeto.

Palavras - Chave — Responsabilidade Social, Projeto In'formar, Comunidades Pilar e Peixinhos.

\section{INTRODUÇÃO}

A responsabilidade social corporativa surgiu a partir dos anos 60, nos Estados Unidos, e no início da década de 70, na Europa. O primeiro Balanço Social foi realizado na França, em 1972, pela empresa Singer. Neste mesmo país, em 1977, foi aprovada lei que torna obrigatória a realização de balanços sociais periódicos para todas as empresas com mais de 700 funcionários, posteriormente alterada para abarcar empresas com mais de 300 empregados. Portugal, em 1985, também promulgou lei que torna 
obrigatória a apresentação do balanço social por empresas com mais de 100 empregados. No Brasil em 1984, foi elaborado o primeiro balanço social pela empresa Nitro fértil. Entretanto, foi na década de 90 que os princípios da responsabilidade empresarial ganhou visibilidade. Em 1992, houve a publicação da Agenda 21, durante a $2^{\text {a }}$ Conferência Mundial do Meio Ambiente - a ECO 92 - realizada no Rio de Janeiro (TEXEIRA, 2004).

A esse respeito, posteriormente, foi dado mais um passo com a criação da ISO14000, certificado que atesta a gestão ambiental de empresas. Em 1997 é criado outro padrão de certificação: o SA8000, que visa aprimorar as condições de trabalho. O SA8000 foi fruto do movimento internacional pela adoção e uniformização dos relatórios sócio-ambientais publicados pelas empresas - o Global Reporting Initiative (GRI) - em parceria com o Programa Ambiental das Nações Unidas (UNEP). Baseia-se em normas internacionais de direitos humanos e nas convenções da Organização Internacional do Trabalho (OIT).

Em 1999, é criada, pelo Institute of Social and Ethical Accountability, nova norma, a AA1000, que engloba o processo de levantamento de informações, auditoria e relato social e ético, com enfoque nas partes interessadas. Essa norma passou a ser a ferramenta mais abrangente para a gestão da responsabilidade social corporativa. Outra importante iniciativa para ampliação da participação das empresas na resolução de problemas sócio-ambientais foi o lançamento, em 2000, do Global Compact (Pacto Global), pelas Nações Unidas, visando promover e implementar nove princípios nas áreas de direitos humanos, trabalho e meio ambiente (TEXEIRA, 2004).

Atualmente responsabilidade social é um tema de grande relevância nos principais centros da economia mundial. Nos estados Unidos e na Europa proliferam os fundos de centros formados por ações de empresas socialmente responsáveis. Como por exemplo: Sustainability Index, da dow Janes, que enfatiza a necessidade de integração dos fatores econômicos, ambientais e sociais nas estratégias de negócios das empresas (INSTITUTO ETHOS, 2006).

\section{Procedimentos Metodológicos}

Este trabalho caracteriza-se como um estudo predominante qualitativo. Através de uma pesquisa bibliográfica procurou-se analisar o projeto de responsabilidade social desenvolvido pelo Porto Digital e que é intitulado IN'FORMAR.

\section{PRINCÍPIOS DA RESPONSABILIDADE SOCIAL}

Os princípios éticos e a busca de qualidade nas relações são manifestações de responsabilidade social empresarial. Numa época em que os negócios não podem mais se dar em segredo absoluto, a transparência passou a ser a alma dos negócios: tornou-se um fator de legitimidade social e um atributo positivo para a reputação das empresas. Tendo em vista que relações de qualidade constroem-se a partir de valores e condutas capazes de satisfazer necessidades e interesses dos parceiros, gerando valor para todos. Hoje, os conceitos que norteiam uma gestão socialmente responsável é a relação ética e transparente com todos os públicos que se relacionam com a empresa. O Instituto Ethos (2004), define o conceito de Responsabilidade Social empresarial (RSE) da seguinte forma:

É a forma de gestão que se define pela relação ética e transparente da empresa com todos os públicos com os quais ela se relaciona e pelo estabelecimento de metas empresariais compatíveis com o desenvolvimento sustentável da sociedade, preservando 
recursos ambientais e culturais para gerações futuras, respeitando a diversidade $e$ promovendo a redução das desigualdades sociais.

\subsection{Empresas com Foco na Responsabilidade Social Empresarial (RSE)}

Um dos traços mais impactantes da recente evolução da economia mundial tem sido integração dos mercados e quebra das barreiras comerciais. $\mathrm{Na}$ era da informação, da nova economia, são profundas as mudanças no modo das sociedades se organizarem. Em curto espaço de tempo, as empresas viram-se compelidas a mudar radicalmente suas estratégias de negócios e padrões gerenciais para enfrentar os desafios e aproveitar as oportunidades (INSTITUTO ETHOS, 2007).

No Brasil, os resultados finais da segunda edição da Pesquisa Ação Social das Empresas, realizada pelo Ipea, com empresas de todo o Brasil, apontam um crescimento significativo, entre 2000 e 2004, na proporção de empresas privadas brasileiras que realizaram ações em beneficio das comunidades. A partir da realização desta segunda edição da pesquisa tornou-se possível iniciar a construção, de maneira inédita, de uma serie histórica da evolução do comportamento da iniciativa privada na área social desde finais da década de 1990 (IPEA, 2006) conforme gráfico abaixo:

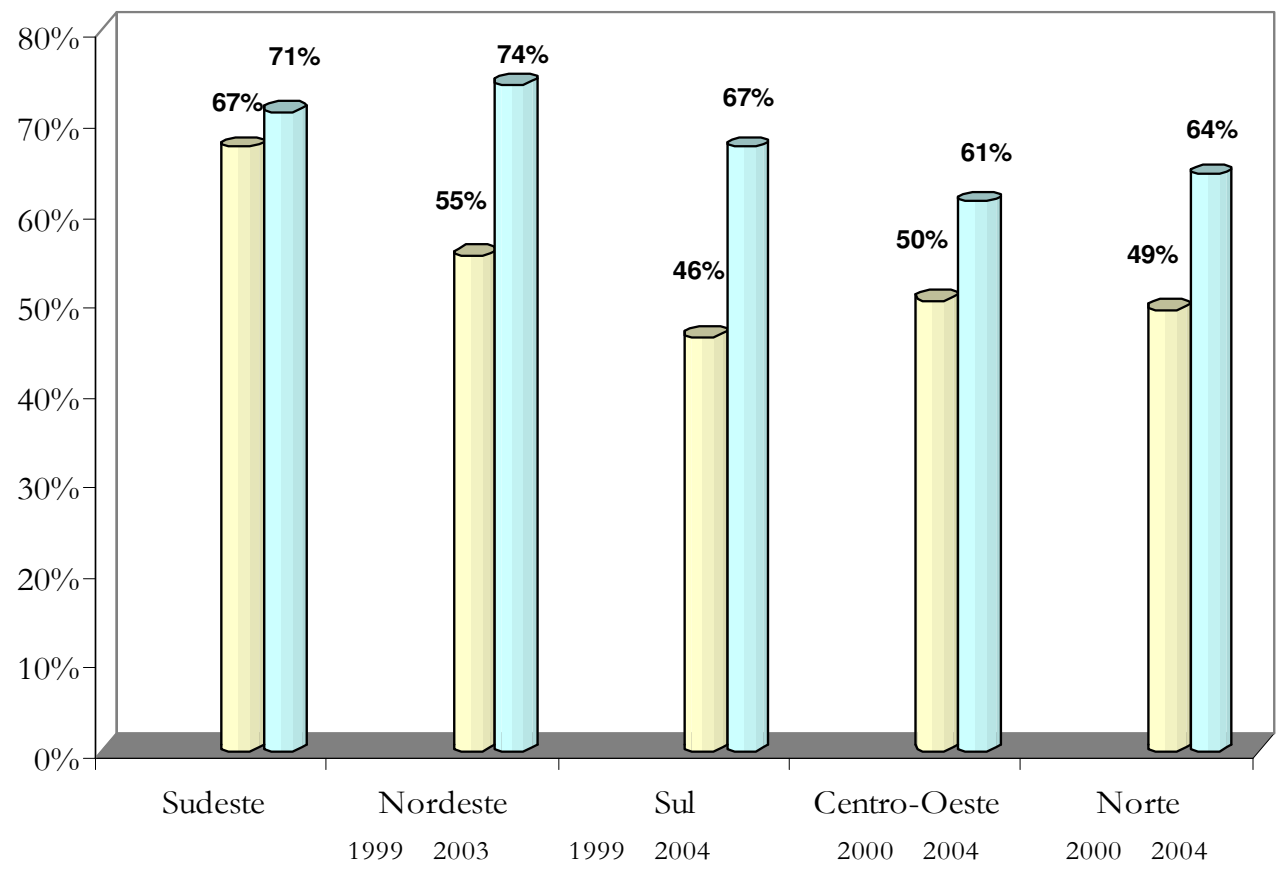

Fonte :Pesquis a Ação Socialdas Empresas no Brasil - IPEA/DISOC (2006)

Gráfico 1(3) - Participação das Empresas em Ações Sociais para a Comunidade 2006.

\subsection{Responsabilidade Social Empresarial no Brasil}

Um conceito que também vem sendo utilizado no Brasil com sentido semelhante ao de responsabilidade social empresarial é o de "cidadania empresarial". Segundo Martinelli (1997), dentro 
da sociedade o setor empresarial é o detentor do maior acervo de recursos potencialmente mobilizáveis e as empresas podem relacionar-se com a sociedade assumindo diferentes posturas. A empresa-cidadã seria aquela que adota a posição proativa de querer contribuir para encaminhar soluções para os problemas sociais. Segundo Rhoden (1996), o conceito de cidadania empresarial encampa a noção de co-responsabilidade da empresa pelos problemas da sociedade, e define como empresa-cidadã "aquela que não foge aos compromissos de trabalhar para a melhoria da qualidade de vida de toda a sociedade".

No Brasil, o movimento de valorização da responsabilidade social empresarial ganhou forte impulso na década de 90, através da ação de entidades não governamentais, institutos de pesquisa e empresas sensibilizadas para a questão. O trabalho do Instituto Brasileiro de Análises Sociais e Econômicas - IBASE na promoção do Balanço social é uma das suas expressões e tem logrado progressiva repercussão. Outro símbolo dos avanços da RSE é obtenção de certificados de padrão de qualidade e de adequação ambiental, como as normas ISO, alcançadas por centenas de empresas brasileiras. A criação dos Indicadores Ethos também faz parte do esforço na disseminação da responsabilidade social no Brasil os Indicadores Ethos, ao mesmo tempo em que servem de instrumento de avaliação para as empresas, reforçam a tomada de consciência dos empresários e da sociedade brasileira sobre o tema. Veja gráficos abaixo de indicadores de RSE no Brasil.



Gráfico 2(3) - Indicadores Ethos de Responsabilidade Social Empresarial por Região 2006.

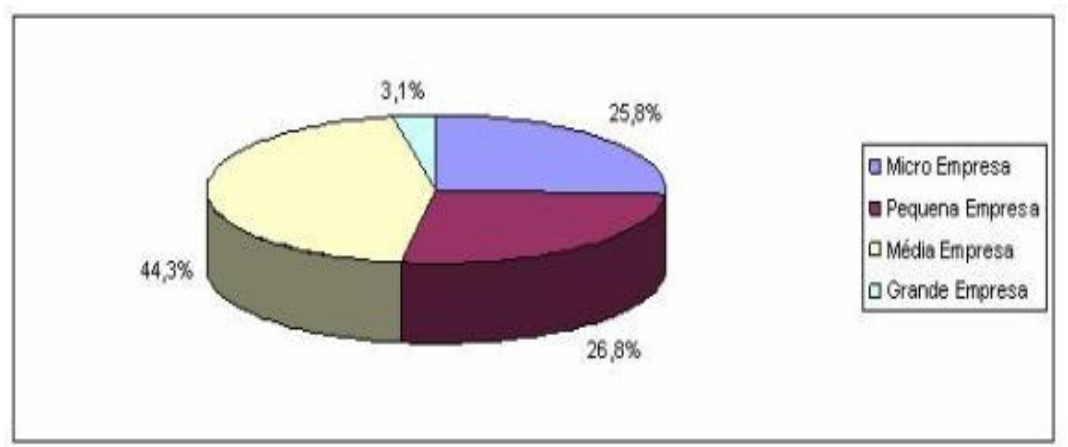

Gráfico 3(3) - Indicadores Ethos-Sebrae de Responsabilidade Social Empresarial por Porte 2006.

\section{INICIATIVAS DAS EMPRESAS}

Em 1984, o primeiro Balanço Social brasileiro foi elaborado pela empresa Nitrofértil. Seguiramse os relatórios do Sistema Telebrás e, no início da década de 90, o do Banespa.

Entretanto, foi apenas na década de 90 que os princípios da responsabilidade empresarial corporativa começaram a, efetivamente, ganhar visibilidade e que as empresas passaram a incorporar essa prática à 
sua gestão e a divulgar relatórios sociais anuais. Um sinal do avanço do comprometimento das empresas com causas sociais e ambientais são os certificados de padrão de qualidade e de adequação ambiental, como as normas ISO, perseguidos por centenas de empresas no Brasil (TEXEIRA, 2004).

\subsection{Iniciativas de Institutos - Fides, Ibase e Instituto Ethos}

A primeira iniciativa brasileira de elaborar um modelo de divulgação de atividades sociais data da década de 80 e foi realizada pela Fundação Instituto de Desenvolvimento Empresarial e Social (Fides). Em 1997, o Instituto Brasileiro de Análises Sociais e Econômicas (Ibase), sob a liderança do sociólogo Herbert de Souza, iniciou campanha para que as empresas incorporassem o bem-estar da comunidade às suas atividades. Nas palavras de Herbert de Souza, tratava-se de chegar “... ao lucro sem ultrapassar os limites sociais". Já no final dos anos 90, o Ibase desenvolveu um modelo de Balanço Social e criou o Selo Balanço Social Ibase/Betinho. O Selo é conferido, anualmente, às empresas que publicam o Balanço Social, no modelo sugerido pelo Ibase, utilizando a metodologia e os critérios propostos. O Selo atesta que a empresa que o recebeu está comprometida com a qualidade de vida de seus funcionários, da comunidade e do meio ambiente (TEXEIRA, 2004).

Com o intuito de debater e implementar a responsabilidade social entre o empresariado é criado, em 1998, o Instituto Ethos. Em 2000, esse Instituto publica a primeira versão dos Indicadores Ethos de Responsabilidade Social Empresarial: "uma ferramenta de aprendizado e avaliação da gestão da empresa no que se refere à incorporação de práticas de responsabilidade social empresarial ao planejamento de estratégias e ao monitoramento do desempenho geral da empresa" (Indicadores Ethos de Responsabilidade Social Empresarial).

Lança também, em 2001, a primeira versão do Guia de Elaboração do Balanço Social, dando continuidade aos trabalhos da Fides e do Ibase (INSTITUTO ETHOS, 2001).

O Guia do Instituto Ethos prevê que as empresas prestem informações sobre si mesmas estrutura e funcionamento, princípios e valores - e sobre a atividade empresarial - indicadores de desempenho financeiro e social. Os indicadores sociais, por sua vez, reúnem informações acerca das diversas partes envolvidas, direta ou indiretamente, na atividade empresarial - público interno, fornecedores, consumidores/clientes, comunidade, governo e sociedade em geral. Para cada participante, relacionam-se indicadores qualitativos e quantitativos (INSTITUTO ETHOS, 2007).

\subsection{O Porto Digital e Seus Projetos de Responsabilidade Social}

O Porto Digital é uma instituição sem fins lucrativos e é qualificada como uma organização da sociedade civil de interesse público (OSCIP). O instituto tem como objetivo principal a promoção da qualidade de vida e do bem estar social através da utilização das tecnologias da informação e comunicação (TICs). Essas ações de cidadania, inclusão digital e social têm como meta estender os benefícios gerados pelo parque de ciência a grupos de pessoas da sociedade econômica e socialmente excluídas, gerando condições de trabalho em todos os níveis, como também riquezas (DIÁRIO DE PERNAMBUCO, 2003).

O Porto Digital é um Arranjo Produtivo de Tecnologia da Informação e Comunicação, com foco no desenvolvimento de software, que está instalado no Bairro do Recife. É resultado do ambiente de inovação que se consolidou em Pernambuco nas últimas décadas.

Hoje, Pernambuco se insere no cenário mundial por seu capital humano, empreendedorismo e inovação. Dos engenhos de açúcar para uma economia baseada em serviços e com uma participação crescente do setor de TIC no PIB pernambucano. De acordo com dados da Condepe, referentes a 2003, 
(Agência Estadual de Planejamento e Pesquisas de Pernambuco), o setor responde por 3.5\% do PIB de Pernambuco (INSTITUTO PORTO DIGITAL, 2003).

Nesse contexto de produzir conhecimento localmente e exportar serviços de valor agregado para o mundo, surgiu o Porto Digital, em julho de 2000.

Um projeto de desenvolvimento econômico que agrega investimentos públicos, iniciativa privada e universidades, compondo um sistema local de inovação que tem, atualmente, 103 instituições entre empresas de TIC, serviços especializados e órgãos de fomento. Em sete anos

de operação, o Porto Digital transferiu para o Bairro, mais de 3.500 postos de trabalho, atraindo empresas de outras regiões do País e empresas multinacionais, abrigando, ainda, quatro centros de tecnologia (INSTITUTO PORTO DIGITAL, 2007).

Os recursos iniciais de $\mathrm{R} \$ 33$ milhões vieram do Governo do Estado, destinados a criar a infraestrutura e as condições necessárias para a implantação e operação do Porto Digital, que tem como missão inserir Pernambuco no cenário tecnológico mundial.

Usando as Tecnologias da Informação e Comunicação, o Instituto Porto Digital fornece as ferramentas para que jovens desfavorecidos possam tornar-se profissionais transformando sua realidade em função das necessidades do futuro, tornando-os mais capacitados para competir na nova realidade sócio-econômica.

Além disso, contribui para a eliminação da pobreza através da concepção, coordenação e execução de projetos e programas de inovação, criação e difusão de conhecimento (DIÁRIO DE PERNAMBUCO, 2003).

A escolha da apresentação do Projeto In'formar se deu após analise de outros projetos sociais desenvolvidos pelo Porto Digital e consideravelmente por este ser inovador, auto-sustentável e desafiador uma vez que partiu da premissa de trazer mudanças efetivas na vida dos jovens e de suas comunidades. Gerou empreendimento com a criação das agências de prestação de serviços tecnológicos e afins, a partir das comunidades, mas com visão de mercado. O diferencial dessa ação está no escopo da idéia do trabalho em rede tanto digital como social. Atualmente as Agências do Pilar e Peixinhos, situadas fora do ambiente do Porto Digital constroem uma perspectiva de futuro fora dos marcos da exclusão Social e Digital em que antes viviam. O Porto Digital mantém seu apoio e a retaguarda até que possam obter sua autonomia completa.

\section{O Projeto IN'FORMAR}

Este projeto foi desenhado e submetido pelo Núcleo de Gestão do Porto Digital ao Programa InfoDev - Information for Development do Banco Mundial em setembro de 2002, sob o título “News@Work: individual and community development through an e-news generation and dissemination network. Teve seu nome alterado no primeiro encontro realizado na comunidade do Pilar, a equipe do projeto verificou que o nome em Inglês "News@work” era muito difícil de ser pronunciado pelas pessoas da Comunidade, que mesmo após saberem seu significado preferiram um nome em Português. Por esta razão, foi dado ao projeto um segundo nome: "IN'FORMAR" (INSTITUTO PORTO DIGITAL, 2003), (NEWS@WORK, 2004).

A solicitação original para a realização do projeto era de US\$246.000,00 para uma execução de 02 anos, com 150 jovens participantes. No final de 2002, o projeto foi aprovado pelo InfoDev com recursos de US\$150.000,00 para 100 jovens, ao invés dos 150 para o qual tinha sido proposto. Em julho 
de 2003 a primeira parte dos recursos foi recebida pelo Núcleo de Gestão do Porto Digital e, em agosto de 2003, a execução do projeto foi iniciada. Dois novos parceiros se integraram a realização projeto no seu início, a Secretaria de Desenvolvimento Social e Cidadania do Governo de Pernambuco e a Prefeitura da Cidade do Recife. Ao longo do desenvolvimento do projeto, novas parcerias beneficiaram os jovens das comunidades escolhidas (INSTITUTO PORTO DIGITAL, 2003).

O projeto trabalhou com duas comunidades de baixa renda da Região Metropolitana do Recife e Olinda, no Estado de Pernambuco. As comunidades escolhidas foram Pilar e Peixinhos, localizadas em áreas carentes da cidade, apresentando altos índices de pobreza, má nutrição, analfabetismo, violência, drogas e outros problemas sociais e econômicos. As comunidades possuem perfis diferentes em relação às suas organizações comunitárias. Isto foi muito importante para o desenvolvimento do projeto, uma vez que ele desenvolveu e aplicou estratégias para socialização das comunidades. Então, tendo duas comunidades com níveis distintos de organização permitiu a realização de estudos comparativos da eficácia destas estratégias. O projeto concentrou suas ações na população de 14 a 24 anos de idade por ser a faixa etária com maior risco de envolvimento em prostituição, drogas e crimes. Por outro lado, apresentam um alto nível de resposta e mobilização para projetos de inclusão social (INSTITUTO PORTO DIGITAL, 2003).

\subsection{Comunidade do Pilar}

A Comunidade do Pilar fica situada em uma ilha, na área histórica e central da cidade do Recife, conhecida como Bairro do Recife. A ocupação data o início dos anos 70 (por volta de 1971), quando a população pobre invadiu uma área urbana abandonada pelo Porto do Recife. Em outubro de 2001, a população era composta de 1.052 habitantes ocupando 463 barracos ou casas construídas de forma precária. A Comunidade do Pilar não possui organização comunitária, a única escola situada no local oferece turmas apenas até o ensino fundamental I, uma grande parte da população é flutuante, em grande parte por causa do tráfico de drogas intenso no local. Fica localizada em área portuária, com intensa prostituição, inclusive infantil (INSTITUTO PORTO DIGITAL, 2003).

\subsection{Comunidade de Peixinhos}

Situada numa área da Região Metropolitana do Recife (RMR) conhecida como Beberibe. Esta é uma das áreas mais densamente populosa da RMR com mais de 550.000 habitantes e 6.750 habitantes/Km2. Também umas das áreas mais pobres, com $63 \%$ da população economicamente ativa recebe menos que dois salários mínimos e cerca de 35\% da população tem menos de 3 anos de educação formal. Segundo dados da Agência Condepe/Fidem, a área de Beberibe tem mais de 170 assentamentos pobres e muito pobres espalhados nos morros e beirados do rio. Peixinhos é um dos bairros mais pobres (INSTITUTO PORTO DIGITAL, 2003).

\subsection{Características e Seleção do Público}

Os critérios de seleção do público consideraram suas condições de vulnerabilidade não como elementos de exclusão, mas como desafios. Assim, o projeto incluiu em seu público todos os inscritos em situação de analfabetismo, os que apresentavam dificuldades de aprendizagem e cognição e, sobretudo, os que estavam envolvidos com situação de exploração do trabalho infantil, principalmente em suas piores formas. Para esse público, foi proporcionada uma formação de mais de 1.000 horas, com computação básica e avançada, códigos e linguagens (noções de português e matemática), pesquisa 
social e comunicação (fotografia e vídeo). O investimento nesses adolescentes não foi apenas no campo das competências formais. Em função do histórico de vida, da baixa auto-estima, das dificuldades vivenciadas no dia a dia, o projeto contou, permanentemente, com o apoio de uma assistente social (que desenvolveu ações de apoio junto às famílias e de acompanhamento escolar) e de uma psicóloga, que desenvolveu um trabalho em grupo e atendimentos individuais, visando apoiar, os que estavam em situações limite, a prosseguir construindo um futuro diferente. Ao final, o projeto previu a montagem de uma Agência de Notícias Digital em cada uma das comunidades "Pilar e Peixinhos", a ser operada pelos próprios adolescentes. Um espaço de produção de idéias, informações e conhecimentos, de protagonismo e de contato com o mundo digital. (INSTITUTO PORTO DIGITAL, 2003).

O projeto IN'FORMAR, depois de desenvolver sua metodologia e conteúdo, passou a ser a principal linha de atuação do Porto Digital, na área de formação, voltada para crianças e adolescentes em situação de alta vulnerabilidade (INSTITUTO PORTO DIGITAL, 2003).

\subsection{Objetivos Gerais e Específicos do Projeto In'formar}

O principal objetivo deste projeto é utilizar as Tecnologias da Informação e Comunicação (TICs) como meio de alavancar a inclusão social e o empoderamento de jovens vulneráveis socialmente. A formação de lideranças juvenis com outras informações, conhecimentos e valores deve contribuir com o processo de inclusão social desejado. Este empoderamento aconteceu tanto individualmente como nas comunidades dos jovens. O projeto transformou a forma como estes moradores viam suas comunidades, passando a se interessar mais por estas. Isto tornou os moradores mais interativos, capazes de brigar por seus direitos e a exigir uma melhor qualidade de vida. Estes objetivos puderam ser atingidos pelo desenvolvimento das seguintes ações e a produção dos respectivos resultados: Capacitação de 100 jovens de 2 comunidades de baixa renda na instalação, operação e sustentação de Agências de Notícias Digitais, incluindo cursos em: Empreendedorismo, Gerenciamento de Negócios, Comunicação, Redes Digitais, Design para a WEB, Manutenção de Computadores, Vídeo e Fotografia Digital (INSTITUTO PORTO DIGITAL, 2003).

\subsection{Alguns Relatos e Constatação do Projeto In'formar}

A Ação Social desenvolvida pelo Porto Digital no projeto IN'FORMAR esta sendo de grande importância nas mudanças de perspectivas dos jovens participantes e membros das comunidades envolvidas. Para muitos desses jovens estarem no projeto, significou estar longe do crime ou da marginalidade através de uma inserção diferenciada no mundo do trabalho e na geração de renda. Como mostram logo abaixo, alguns depoimentos dentre vários:

"No ano passado eu desisti de estudar por falta de interesse, só queria ficar na rua. Mas aí fiquei sabendo do projeto que ia abrir e que para participar tinha que estar na escola. Então eu me matriculei e estou terminado. O que me incentivou a ficar na escola até o final do ano foi o projeto."

Paulo Ricardo Severino da Silva, 17 anos.

"Eu voltei a estudar por dois motivos um foi a pressão do meu pai e o outro foi o estímulo por causa do projeto. Muitos professores conversaram comigo e me incentivaram a permanecer até o final do ano. Eu acho que se eu não estivesse no projeto não teria voltado a estudar."

Eduardo Xavier da Silva, 23 anos. 
"O Projeto me ajudou a amadurecer e enfrentar algumas situações difíceis na minha vida. Não sei se teria conseguido sem a ajuda do projeto. Graças a Deus diante de tudo, nem eu nem meus irmãos corremos para as drogas, pois sabemos na pele que este é o pior caminho."

Rosângela Nascimento, 17 anos.

Percebe-se através das entrevistas com os jovens participantes do projeto, uma clara indicação da redução de danos promovida pelo mesmo, quando o jovem revela sua certa mudança comportamental com relação aos estudos. As atividades do projeto, além de elevarem a auto-estima, também desenvolveu, um sentimento de comprometimento e desejo para afastar-se do caminho das drogas e da violência, redução dos índices de evasão escolar e outros.

\section{CONCLUSÕES}

A partir do que foi apresentado neste trabalho, pode-se concluir que a responsabilidade social vem ganhando crescente relevância no mundo empresarial por empresas de todos os portes, embora mais difundido no segmento de grande porte.

Após a década de 90 a responsabilidade social empresarial ganhou força no Brasil e no mundo, tendo adesão crescente das empresas, que passaram a considerar o conceito como parte das suas diretrizes de suas estratégias. A busca de excelência pelas empresas passa a ter como objetivo a qualidade nas relações e a sustentabilidade econômica, social e ambiental.

Nesta revolução cultural, empresas estão escolhendo estratégias que possam ao mesmo tempo garantir uma posição de destaque e de perenidade em longo tempo. Tendo em vista que as empresas socialmente responsáveis, que pensam não somente no lucro, mas, acima de tudo, no ser humano, são mais valorizadas e reconhecidas.

No Brasil, as pesquisas do Ipea (Instituto de pesquisa Econômica Aplicada), apontam um crescimento significativo entre 2000 e 2004 de empresas privadas que realizam ações sociais em beneficio das comunidades. Apesar, do pouco incentivo pela política de benefícios tributários e da grande maioria acreditarem que a obrigação do Estado cuidar do social, atualmente são mais de 600 mil empresas que atuam voluntariamente em ações sociais.

No estudo de caso apresentado do Porto Digital, o Instituto parte da premissa de que não há desenvolvimento tecnológico viável com exclusão social. Dessa forma, o Porto Digital fornece as ferramentas para que jovens desfavorecidos possam tornar-se profissionais transformando sua realidade em função das necessidades do futuro, tornando-os mais capacitados para competir na nova realidade sócio-econômica. Além disso, contribui para a eliminação da pobreza através da concepção, coordenação e execução de projetos e programas de inovação, criação e difusão de conhecimento. Como por exemplo, o projeto In'formar.

O projeto In'formar gerou aos jovens participantes novas oportunidades, o que tem lhes garantido uma inserção sustentável no mercado de trabalho. Sendo um projeto de longa duração, com exigências de freqüência à escola, naturalmente diminui o risco de incidência da subutilização de mãode-obra, pois reduz a exposição destes a esta problemática. Além de preencher os horários vagos, possibilita inserção sustentada no mercado, passa a gerar a expectativa de que é preciso investir em seu próprio potencial e que isso possibilita retornos inclusive financeiros mais seguro e duradouros.

O projeto promoveu a inclusão e familiarização dos jovens em um novo contexto: o mercado de tecnologia. As empresas com os quais os jovens passaram a se relacionar para prestar serviços são de um segmento competitivo, moderno e com demandas específicas. Esses novos relacionamentos propuseram 
a estes jovens a construção de novos valores, especialmente a crença que outro tipo de vida é possível, diferente da visão de futuro que tinha antes de participarem do projeto.

\section{REFERENCIAS}

CADERNO ESPECIAL. Porto digital. Diário de Pernambuco, Recife, 21 ago.2003, p. E1 - E10.

ETHOS. Ética e qualidade nas relações. Disponível na internet via http://www.ethos.org.br/docs/conceitos_praticas/indicadores/responsabilidade/contexto_brasileiro.asp Acessado em 03 de dezembro de 2007.

Indicadores ethos-sebrae de responsabilidade social empresarial para micro e pequenas empresas 2006. Disponível na internet via

http://www.ethos.org.br/docs/conceitos_praticas/indicadores/resultados/resultados_2006/sebrae/setores.a sp Acessado em 03 de dezembro de 2007.

INSTITUTO PORTO DIGITAL. Exclusão digital.

www2.fgv.br/ibre/cps/mapa_exclusao/Site/PanoDeFundo/Internet/Internet34.pdf Acessado em 03 de outubro de 2008

IPEA. Brasil - Resultados finais da segunda edição 2006. Disponível na internet via http://www.ipea.gov.br/asocial/ Acessado em 03 de dezembro de 2007.

MARTINELLI, A. C., Empresa-cidadã: uma visão inovadora para uma ação transformadora. In: IOSCHPE, Evelyn B. Terceiro setor: desenvolvimento social sustentado, São Paulo, Paz e Terra, 1997, p.84.

PROJETO NEWS@WORK de Inclusão Social - Revista bimestral de circulação interna, 2004.

PORTODIGITAL. Inovação, empreendedorismo e capital humano. Disponível na internet via http://www.portodigital.org/ Acessado em 18 de outubro de 2007.

ROHDEN, F., Filantropia empresarial: a emergência de novos conceitos e práticas, Anuais do Seminário Empresa Social, São Paulo, 1996, p.46, citado em ASHLEY, P. A., Responsabilidade social corporativa e cidadania empresarial: uma análise conceitual comparativa, paper a ser apresentado no ENAMPAD, 2000.

TEIXEIRA, L. S., Responsabilidade social empresarial; Câmara dos deputados, Brasília, 2004. 